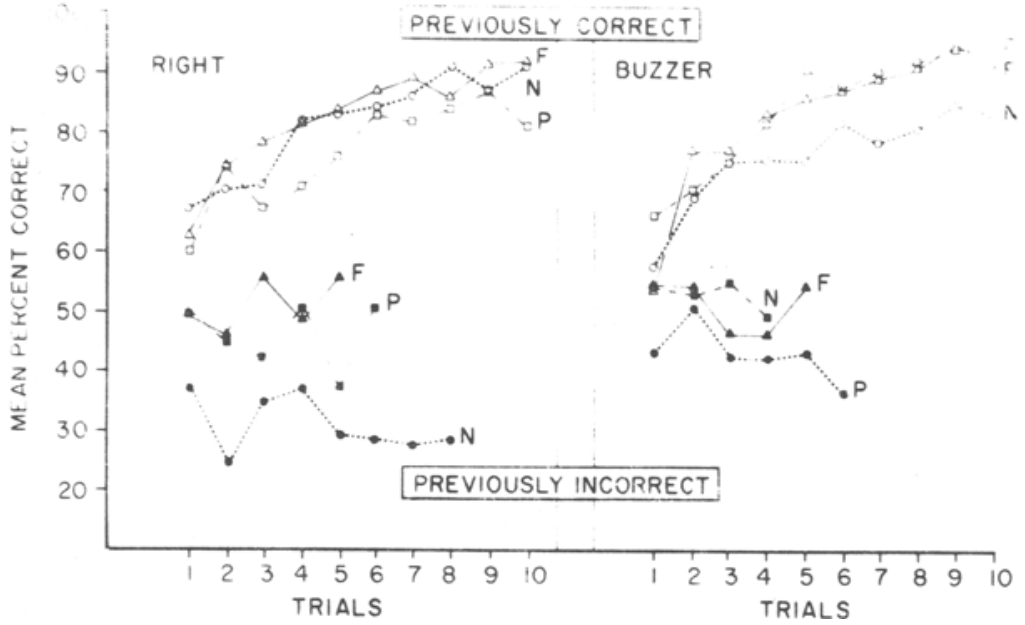

instructional conditions, but that blank following incorrect responses was less effective in this group in producing a shif to correct responses. The presence of the eight "repeaters" in the N-R condition contributed heavily to the latter result However, when the records of all "repeaters" were eliminated, the curve of per cent correct following incorrect for the N-R group rose, but was still markedly lower than that of the other two instructional groups. Thus, the performance inferiority of the noninformed Ss reinforced by "right" appears to be due to the relative ineffectiveness of blank, rather than of the overt reinforcer, some Ss reacting to blank as if it were "right" ("repeaters") and others as if it were informationally ambiguous or meaningless.

In the noninformed-buzzer condition, blank was also less effective than it was in the other buzzer conditions. However, the discrepancy was less marked than in the case of the groups reinforced by "right," primarily because of the smaller number of "repeaters" in the N-B group. The major difference between the N-R and N-B conditions, however, concerned the effects of the overt reinforcer. While "right" was as effective a positive reinforcer in the N-R group as in the other groups reinforced by "right," the buzzer in the N-B group was less effective a positive reinforcer than it was in the F-B and P-B conditions in which Ss had been given an explanation of its meaning. Only one S, however, appeared to "misinterpret" the buzzer, i.e., re acting to it as if it signaled incorrect responses by systematically coming to select more and more responses followed by blank.

The behavior of $S s$ in the partially-informed buzzer group was in all respects indistinguishable from that of the fully-informed group. The P-R group, however, did not perform as well as the F-R, a result only partly explicable by the presence of two "repeaters" among the P-R Ss. As may be seen in Fig. 1, blank was somewhat less effective as a negative reinforcer than in the $F \cdot R$ group, and "right" was less effective as a positive reinforcer than in either the F-R or N-R groups. The latter results, in particular, suggest that the poorer performance of the P-R Ss in comparison to F-R may partially be the result of sampling error. It would, none theless, seem wise in studies in which it is desirable for Ss to understand the reinforcement procedures to explain the
EDITH D. NEIMARK and MARCIA HORN, Douglass College, Rutgers, The State University, New Brunswick, N.J. 08903

Data on performance of a 2-year-old girl on a series of fixed-trial discrimination and oddity problems are presented. There is evidence of the development of a discrimination-learning set, and, possibly, of an oddity set as well. After reviewing existing evidence, it is suggested that 24-30 months may constitute a lower limit for the attainment of learning set in humans.

Harlow, Harlow, Rueping, \& Mason (1960) have presented evidence that learning-set formation in the young rhesus is a function of age rather than of prior training, and that young monkeys below 90 days of age do not acquire a learning set. Comparison of the available evidence on learning set in children suggests a similar conclusion. Although Levinson \& Reese (1967) found no correlation between CA and trials to criterion for their 36- to 66-month-old Ss, Koch \& Meyer (1959) reported a correlation of -.59 between MA and trials to criterion for children 29-66 months old Haves. Thompson, and Hayes (1953) report data for six children: the two
Fig. 1. Mean per cent correct on given trial for previously correct and incorrect responses for the three instructional groups in the right and buzzer conditions. (Analyses of incorrect response discontinued when one or more Ss reached criterion of perfect performance.)

informational characteristics of not only the overt reinforcers but also of blank.

\section{REFERENCES}

BUSS, A. H., \& BUSS, E. H. The effect of verbal reinforcement combinations on conceptual learning. Journal of Experimental Psychology. 1956, 52, 283-287.

CAIRNS, R. B. Informational properties of verbal and nonverbal events. Journal of Personality \& Social Psychology, 1967, 5, 35 3-357.

CURRY. C. The effects of verbal reinforcement combinations on kearning in children. Journal of Experimental Psychology, 1960, 59,434.

SPENCE. J.T. Verbal discrimination performance as a function of instructions and verbal reinforcement combinations in normal and retarded children. Child Development. 1966. $37,269-281$

\section{NOTE}

1. The investigation was supported, in part, by Grant HD01980 from the National Institute of Mental Health.

\title{
Development of discrimination and oddity learning set in a two-year-old girl
}

6-year-olds and a bright 4year-old learned rapidly, a normal 4-year-old learned more slowly, and the two 2-year-olds gave no evidence of acquiring a learning set at all. Thus, there is some question about whether or not a child of $2-21 / 2$ years can develop a discrimination leaming set. The present experiment attempts to answer that question and, in addition, to provide evidence on performance on oddity problems by the 2-year-old. A review of the literature showed there is no evidence of oddity learning in children below 4

\section{SUBJECT}

The sole $S$, daughter of the second author, was tested in her own home over a 3-month period. She was 26 months old at the start of training and was already speaking in sentences. She could accurately discriminate and name colors -at least to the extent of correct response to a request to select all the blue (red, etc.) from an array of colored cards. By the same criterion she could also discriminate squares from triangles (although she did not initially know the word "triangle," she learned it as a result of this test and used it spontaneously later).

$$
\text { APPARATUS }
$$

A small wooden tray, $12 \times 2 \frac{1}{2}$ in.. with 


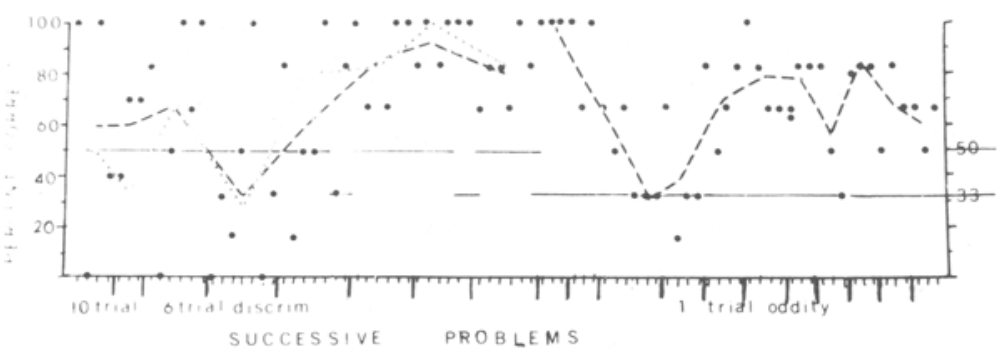

equally spaced circular depressions $1 \frac{1}{4}$ in. in diam, was used. The stimuli consisted of eight small objects and 443 -in. square cards containing a large colored square or one or two smaller colored squares or triangles. A pretzel goldfish or a tiny plastic trinket served as reinforcer on each trial.

\section{PROCEDURE}

The $\mathrm{S}$ was seated at a small table in her living room and presented with the tray containing a trinket in the center depression hidden by a white card and told to remove the card. She was then presented with the tray with two cards and told that a toy was hidden under one of them and that she was to try to find it. For the first two sessions, discriminations between two colors were run for 10 trials each. Thereafter, objects and form cards were also included among the discriminanda and each problem was run for six trials. Initially, the first author served as $E$ for one brief session a week. After five weekly sessions, it was decided to test more frequently and the second author took over for daily or every-other-day sessions as her schedule permitted. Discrimination training continued to attainment of one session of $100 \%$ correct second-trial choice. After an additional postcriterion day (in which criterion level was not maintained), oddity training was begun with card stimuli and six-trial problems. On the second day of oddity training two- to four-trial problems were used; one- to two-trial problems were used in subsequent sessions. For all trials, location of reinforcement was varied randomly within the restriction of $50 \%$ on each side (or $33-1 / 3 \%$, for oddity). A noncorrection procedure was used throughout.

\section{RESULTS}

Figure 1 summarizes per cent correct on successive problem blocks; the first seven points represent 10 -trial blocks, the remaining ones 6-trial blocks. Longer lines along the axis indicate daily sessions. The darker broken line indicates daily mean per cent correct; the lighter line indicates Trial 2 performance within a session. Criterion for the discrimination problems was attained on the seventh daily session (which consisted of four discrimination and two oddity series) after 31 problems or a total of 214 trials. By way of comparison, Levinson \& Reese (1967) report half of their youngest group attaining criterion at the end of two sessions (of 10 four-trial discriminations each); their worst $S s$ required nine sessions.

Although criterion level was not maintained on the postcriterion discrimination session, performance was well above chance. Perfect performance on the first session of six-trial oddity problems suggests perfect positive transfer from the discrimination learning set; but this high level of performance was not maintained with two- to four-trial problems. Since $S$ was giving increasing evidence of getting "bored with the game," E attempted to revive interest with new discriminanda: number-concept flash cards containing pictures of $n$ common objects. Oddity problems at so high a level of abstraction are obviously beyond a 2-year-old, as is shown by the sharp drop to a chance level of performance for 18 trials. Although performance improved again with return to familiar material, this frustrating experience undoubtedly contributed to erratic performance on the later sessions.

\section{DISCUSSION}

For at least the first two sessions, $\mathrm{S}$ was clearly responding solely on the basis of object preference or avoidance; ${ }^{2}$ thus, the high incidence of $0 \%$ or $100 \%$ performance. Although object preference is a common source of error among naive rhesus monkeys, it is not commonly reported among preschool children. Once the object preference responding was eliminated, a discrimination learning set was developed quite rapidly. It was not possible to distinguish other consistent hypotheses during the transition. During many of the precriterion problems, S spontaneously described the stimuli: "under the yellow," "not under the black; it's brown, let me try," etc. Although Lunzer \& Hulme (1967) also found spontaneous verbalization among somewhat older normal children-and retarded children as well-they report that it is unrelated to the acquisition of a learning set. There was no verbalization of the oddity principle, but it may be that the requisite concepts are beyond the verbal repertoire of a 2-year-old.

Despite the clear evidence for acquisition of a discrimination learning set (and some suggestion of learning the oddity principle as well), there are grounds for doubt that
Fig. 1. Per cent correct response on successive trial blocks. The first seven points are based upon 10-trial blocks, all later ones upon 6-trial blocks. The longer lines on the axis indicate a daily session. The dark line indicates daily mean for all trials; the lighter broken line is daily mean performance on the second trial. For discrimination problems chance performance is .50 ; for oddity problems it is .33 .

learning set acquisition is within the capability of the average 2-year-old. First, $S$ is probably brighter than average and her MA may well be within the lower limit of previously reported data: ca. 30 months. Second, even with seemingly optimal conditions of attention from liked adults in familiar surroundings at a "game" which inspired great enthusiasm, it was difficult to maintain her attention for the 20-30 min of a daily session. The problem of maintaining attention was aggravated by the requirements of the one-trial oddity problems which necessitated a longer interproblem interval for selecting stimuli, etc. Use of an automated apparatus in an environment free of distraction might obviate some of these difficulties. Until such a study is run, it is reasonable to assume that 2430 months may constitute the lower limit of MA for the attainment of learning set. Whether that limit is imposed by short attention span, inadequate maturation of cognitive capacities, or some combination of the two, may be a question which is not empirically answerable.

\section{REFERENCES}

HAYES, K. J., THOMPSON, R., \& HAYES, C. Discrimination learning set in chimpanzees. Journal of . Comparative \& Physiological Psychology, 1953, 46, 99-107.

HARLOW, H. F., HARLOW, M. K., RUEPING, R R., \& MASON, W. A. Performance of infant monkeys on discrimination learning, delayed response, and discrimination learning set. Journal of Comparative \& Physiological Psychology, 1960, 53, 113-121.

KOCH, M. B., \& MEYER, D. R. A relationship of mental age to learning set formation in the preschool child. Journal of Comparative \& Physiological Psychology, 1959, 52, 387-389. LEVINSON, B., \& REESE, H. W. Patterns of discrimination learning set in preschool children, fifth-graders, college freshmen, and the aged. Monographs of the Society for Research in Child Development, 1967, 32, Serial No. 115.

LUNZER, E. A., \& HULME, I. Discrimination learning and discrimination learning sets in subnormal children. British Journal of Educational Psychology, 1967, 37, 175-187. NOTES

1. This research was supported under Grant No. HD 01725-04 from USPH.

2. Object avoidance was especially obvious in the choice between a pepper shaker and a green plastic beetle (which $S$ called a frog). On each trial, she hesitated for a long while and made comments such as "we not need any frogs," "I not like that frog," etc. 